\title{
MicroRNA-497 regulates cell proliferation in hepatocellular carcinoma
}

\author{
WEN-ZHOU DING ${ }^{1 *}$, QING-FENG NI ${ }^{2 *}$, YE-TING LU ${ }^{3 *}$, LIANG-LIANG KONG ${ }^{4}$, \\ JIAN-JUN YU ${ }^{4}$, LONG-WEI TAN ${ }^{4}$ and LIAN-BAO KONG ${ }^{4}$ \\ ${ }^{1}$ Department of Hepatobiliary Surgery, Nanjing Medical University Affiliated Wuxi Second Hospital, Wuxi 214002; \\ ${ }^{2}$ Department of General Surgery, Affiliated Hospital of Nantong University, Nantong, Jiangsu 226000; \\ ${ }^{3}$ Department of Hepatobiliary and Pancreatic Surgery, Ningbo Lihuili Hospital, Ningbo, Zhejiang 315200; \\ ${ }^{4}$ Department of Liver Transplantation Center, The First Affiliated Hospital of Nanjing Medical University, \\ Nanjing, Jiangsu 210029, P.R. China
}

Received November 15, 2014; Accepted October 23, 2015

DOI: $10.3892 / \mathrm{ol} .2015 .3981$

\begin{abstract}
Hepatocellular carcinoma (HCC) is the most common primary cancer of the liver. MicroRNA-497 (miR-497) is known to be downregulated in several types of human cancer; however, the expression, function and underlying mechanisms of miR-497 in HCC remain unclear. Therefore, the present study investigated miR-497 expression in HCC samples and HCC-derived cell lines using reverse transcription-quantitative polymerase chain reaction. The protein expression of one of the predicted common targets of miR-497, insulin-like growth factor-1 receptor (IGF-1R), was assessed using western blot analyses and immunohistochemistry. The role of miR-497 in regulating the proliferation of HCC-derived cells was also investigated in vitro and in vivo. Of 60 paired specimens from $\mathrm{HCC}$ patients, miR-497 was downregulated in 42 cancer specimens compared with adjacent non-cancer tissues. Western blotting and immunohistochemical analyses revealed that IGF-1R expression was significantly increased in HCC compared to control tissues. In addition, overexpression of miR-497 was observed to inhibit colony formation and tumor growth in $\mathrm{MHCC}-97 \mathrm{H}$ human HCC cells. Conversely, SMMC-7721 human HCC cells transfected with a miR-497 inhibitor exhibited enhanced colony formation and tumor growth. Finally, IGF-1R protein, phosphoinositide 3-kinase/Akt signaling pathway-associated proteins and cyclin pathway-associated proteins were differentially expressed between miR-497-overexpressing cells and
\end{abstract}

Correspondence to: Dr Lian-Bao Kong, Department of Liver Transplantation Center, The First Affiliated Hospital of Nanjing Medical University, 300 Guangzhou Road, Nanjing, Jiangsu 210029, P.R. China

E-mail: lbkong@njmu.edu.cn

${ }^{*}$ Contributed equally

Key words: microRNA-497, hepatocellular carcinoma, proliferation, insulin-like growth factor-1 receptor, phosphoinositide 3-kinase/Akt
miR-497-silenced cells. These results indicate that miR-497 may be a potentially effective gene therapy target.

\section{Introduction}

Hepatocellular carcinoma (HCC) is the fifth most frequent cancer and the third most common cause of cancer-associated mortality worldwide, with $>600,000$ mortalities reported annually $(1,2)$. Over the last few decades, the incidence of HCC has increased in eastern Asia and sub-Saharan Africa $(3,4)$; the estimated number of new cases diagnosed annually increased from 437,000 to 564,000 between 1990 and $2000(1,4)$. Due to the highly aggressive nature of the tumor, and because tumors are highly resistant to traditional treatments, such as chemotherapy and radiation, the 5-year survival rate of $\mathrm{HCC}$ is poor, with an overall survival rate of $<16 \%$ (5). In addition, surgical resection and liver transplantation are restricted, and are suitable only for patients diagnosed with early stage disease (6). It is generally recognized that exploring the underlying molecular mechanisms of HCC initiation and progression in order to search for functional molecular targets may provide a new approach for HCC treatment.

MicroRNAs (miRNAs) are small, endogenous, non-coding RNAs, which act as key post-transcriptional regulators of target-gene expression. They bind primarily to 3'-untranslated regions (3'-UTRs) of target gene mRNAs. This process leads to translational repression or mRNA cleavage $(7,8)$. Recent studies have reported that $>1,000$ human miRNAs have been identified that regulate $\sim 1 / 3$ of the coding genes in the human genome (9). Many of these miRNAs act as tumor suppressors and/or oncogenes, and are involved in cell activities that include development, differentiation, proliferation, apoptosis, metabolism and immunity $(7,10,11)$. Recently, an increasing number of studies have revealed that microRNA-497 (miR-497) levels are decreased in tumors, and that it functions as a tumor suppressor in a number of types of human cancer, including colorectal, gastric, cervical and breast cancers, adrenocortical carcinoma and melanoma (12-20). Similarly, a study by Furuta et al (21) indicated that miR-497 
targets multiple cell cycle regulators and suppresses cell cycle progression in vitro. However, whether miR-497 regulates other target genes in $\mathrm{HCC}$ is unknown.

Insulin-like growth factor-1 receptor (IGF-1R) is a member of the receptor tyrosine kinase family and contains two extracellular $\alpha$ subunits (including the ligand-binding site) and two $\beta$ subunits (with intracellular tyrosine kinase activity) $(22,23)$. IGF-1R has an important role in malignant cell growth and survival, and is highly expressed in malignant tumors in the nervous system, liver, thymus, adrenal cortex, gallbladder, colon, pancreas and lung (24-28). Furthermore, IGF-1R is crucial for activating the phosphoinositide 3-kinase (PI3K)/Akt pathway $(29,30)$, which promotes cell proliferation and survival, and is activated by numerous growth factor receptor tyrosine kinases (31-33). IGF-1R mRNA and protein expression are increased in $\mathrm{HCC}$ and are closely associated with the progression of malignant tumors $(34,35)$. To date, studies have demonstrated that miR-497 targets IGF-1R and has a tumor suppressive role in human cervical cancer (20) and in colorectal cancer (12). However, whether miR-497 functions as a tumor suppressor by directly targeting IGF-1R in HCC remains unclear.

In the current study, the expression levels of miR-497 and IGF-1R were examined in HCC cells and tumor samples. miR-497 overexpression was found to inhibit cell growth, reduce IGF-1R expression and decrease PI3K/Akt pathway activation. Although downregulation of miR-497 contributed to malignant behavior in HCC cells, it increased IGF-1R expression and elevated activation of PI3K/Akt signaling. These results suggest that miR-497 functions as tumor suppressor by targeting IGF-1R in HCC.

\section{Materials and methods}

Ethics statement. The Institutional Animal Care and Use Committee at Nanjing Medical University (Nanjing, China) approved the study protocols for experiments involving human tissue and animals.

Tissue specimens. A total of 60 paired HCC and adjacent non-tumor tissues were evaluated for the expression of miR-497 and IGF-1R. Adjacent non-tumor tissues were $\geq 2 \mathrm{~cm}$ away from the edge of the tumors. All tissues were obtained from patients that had undergone partial hepatectomy at the First Affiliated Hospital of Nanjing Medical University between December 2011 and February 2014. The patient cohort included 49 males and 11 females, with a median age of 58 years (range, 36-66 years). Of the 60 patients, 18 patients exhibited stage A disease, 28 patients exhibited stage $\mathrm{B}$ and 14 patients exhibited stage $\mathrm{C}$ disease, according to the Barcelona Clinic Liver Cancer staging system (36). A total of 35 cases exhibited an HCC mass $>5 \mathrm{~cm}$ in diameter, while 25 cases exhibited an HCC mass with a diameter of $<5 \mathrm{~cm}$. Patients that had undergone treatment prior to surgery were excluded from the study. HCC specimens and adjacent non-tumor tissues were confirmed by pathological examination, and immediately stored in liquid nitrogen post surgery. Written informed consent was obtained from either the patient or the families of the patients.

Liver cancer cell lines. Human HCC cell lines (YY-8103, HepG2, Hep3B, SMMC-7721 and MHCC-97H) and normal human liver cells (L02) were obtained from the Department of Liver Transplantation Center at the First Affiliated Hospital of Nanjing Medical University (Nanjing, China). Cell lines were cultured in Dulbecco's modified Eagle's medium (DMEM) containing 10\% fetal bovine serum (FBS) (both HyClone ${ }^{\mathrm{TM}}$; GE Healthcare Life Sciences, Logan, UT, USA), penicillin (50 U/ml; (Invitrogen ${ }^{\mathrm{TM}}$; Thermo Fisher Scientific, Inc., Carlsbad, CA, USA) and streptomycin $\left(50 \mu \mathrm{g} / \mathrm{ml}\right.$; Invitrogen ${ }^{\mathrm{TM}}$; Thermo Fisher Scientific, Inc.) and propagated in $5 \% \mathrm{CO}_{2}$ in a $37^{\circ} \mathrm{C}$ humidified incubator.

Reverse transcription (RT)-quantitative polymerase chain reaction $(q P C R)$. Total RNA from liver tissue samples and $\mathrm{HCC}$ cell lines were extracted using Invitrogen ${ }^{\mathrm{TM}}$ TRIzol reagent (Thermo Fisher Scientific, Inc.), following the manufacturer's instructions. To determine miRNA expression, total RNA ( $1 \mu \mathrm{l} / \mathrm{sample}$ ) was reverse-transcribed using miRNA-specific stem-loop RT primers, reverse transcriptase, RT buffer, dNTPs and an RNase inhibitor, according to the manufacturer's instructions (TaqMan ${ }^{\circledR}$ MicroRNA Reverse Transcription Kit; Applied Biosystems ${ }^{\mathrm{TM}}$; Thermo Fisher Scientific, Inc.). qPCR was performed using an Applied Biosystems ${ }^{\mathrm{TM}}$ StepOnePlus ${ }^{\mathrm{TM}}$ Real-Time PCR System (Thermo Fisher Scientific, Inc.). The $20-\mu 1$ reaction system contained the corresponding cDNA $(2 \mu \mathrm{l})$, miRNA-specific TaqMan ${ }^{\circledR}$ primers $(1 \mu \mathrm{l})$, TaqMan ${ }^{\circledR}$ Universal PCR Master Mix $(10 \mu \mathrm{l})$ and $\mathrm{ddH}_{2} \mathrm{O}(7 \mu \mathrm{l})$ (Applied Biosystems $^{\mathrm{TM}}$; Thermo Fisher Scientific, Inc.). The PCR conditions were $95^{\circ} \mathrm{C}$ for $10 \mathrm{~min}$, followed by 50 cycles at $95^{\circ} \mathrm{C}$ for $15 \mathrm{sec}$ and $60^{\circ} \mathrm{C}$ for $1 \mathrm{~min}$. RNU6B was used as an endogenous housekeeping control for data normalization of miRNA levels. The comparative threshold cycle $(\mathrm{Ct})$ method was used to measure the relative changes in expression (37); $2^{-\Delta \Delta C t}$ represents the fold-change of expression.

Immunohistochemical staining. All tissues were paraffin-embedded and obtained from the Department of Pathology at the First Affiliated Hospital of Nanjing Medical University. Paraffin-embedded tissues were cut into $4-\mu \mathrm{m}$ sections, and incubated with the rabbit anti-human IGF-1R polyclonal antibody (cat. no. ab39398; Abcam, Cambridge, MA, USA; dilution, 1:100) overnight at $4^{\circ} \mathrm{C}$. SP-9000 Histostain ${ }^{\mathrm{TM}}$-Plus kits (ZSGB-BIO, Beijing, China) were used according to the manufacturer's instructions. Scoring was measured according to the cell cytoplasm staining pattern: 0 , no cytoplasmic staining; 1, weak cytoplasmic staining; 2 , moderate cytoplasmic staining; and 3 , strong cytoplasmic staining.

Cell transfection. The miR-497 mimic, miR-497 inhibitor, miRNA mimic negative control (NC) (a miRNA mimic) and miRNA inhibitor NC were purchased from Shanghai GenePharma Co., Ltd. (Shanghai, China) and were transfected using Lipofectamine $^{\circledR} 2000$ transfection reagent (Invitrogen $^{\mathrm{TM}}$; Thermo Fisher Scientific) according to the manufacturer's instructions. The sequences were as follows: miR-497 mimic, 5'-CAGCAGCACACUGUGGUUUGU-3'; NC, 5'-UUCUCC GAACGUGUCACGUTT-3'; miR-497 inhibitor, 5'-ACAAAC CACAGUGUGCUGCUG-3'; and miRNA inhibitor NC, 5'-CAG UACUUUUGUGUAGUACAA-3'.

Cell proliferation assays. Cells were seeded at a density of 2,000-5,000 cells/well in 96-well plates in $100 \mu$ l complete 
media. Cell Counting Kit-8 (CCK-8; Dojindo Laboratories, Kumamoto, Japan) was used to measure cell viability according to the manufacturer's instructions. Briefly, cells were seeded at a density of 2,000-5,000 cells/well in 96-well plates in $100 \mu \mathrm{l}$ DMEM containing 10\% FBS (HyClone ${ }^{\mathrm{TM}}$; GE Healthcare Life Sciences), penicillin (50 U/1; Invitrogen ${ }^{\mathrm{TM}}$; Thermo Fisher Scientific, Inc.) and streptomycin $(50 \mu \mathrm{g} / \mathrm{ml}$; Invitrogen $^{\mathrm{TM}}$; Thermo Fisher Scientific, Inc.) and cultured for 6 days in $5 \% \mathrm{CO}_{2}$ in a $37^{\circ} \mathrm{C}$ humidified incubator. Next, $10 \mu \mathrm{l} \mathrm{CCK}-8$ solution was added to each well and incubated at $37^{\circ} \mathrm{C}$ for $1 \mathrm{~h}$. The absorbance was then calculated at a wavelength of $450 \mathrm{~nm}$ using a microplate reader (ELX808; BioTek Instruments, Inc., Winooski, VT, USA). Each experiment was repeated at least three times.

Colonyformation assays. To examine the effect of upregulated or downregulated miR-497 expression on the proliferation of HCC cell lines, cells transfected with miR-497 mimics, miR-497 inhibitor, NC and miRNA inhibitor NC were used for colony formation assays. Each cell type was seeded into 6-well plates (500 cells/well) and cultured for 3 weeks. Cultures were stained with $0.4 \%$ crystal violet (Beyotime Biotech, Jiangsu, China). Colonies of $>2 \mathrm{~mm}$ were counted and the mean number of colonies per well was calculated from three wells for each experiment. Each experiment was repeated at least three times.

Soft agar colony formation assays. Cells were transfected with miR-497 mimics, miR-497 inhibitor, NC and miRNA inhibitor $\mathrm{NC}$, suspended in $0.5 \mathrm{ml}$ of $1 \%$ low melting point agarose with complete culture media, and layered on top of $0.5 \mathrm{ml}$ of $2 \%$ low melting point agarose (Department of Liver Transplantation Center, The First Affiliated Hospital of Nanjing Medical University) in 24-well plates. Cell counts varied from 2,000 to 5,000 cells depending on the cell line. Plates were incubated for 2 weeks in a $37^{\circ} \mathrm{C}$ humidified incubator with $5 \% \mathrm{CO}_{2}$. Colonies in at least 6 random microscopic fields were counted (Nikon Eclipse 50i; Nikon Corporation, Tokyo, Japan) and photographed (AxioCam MRc5; Carl Zeiss Shanghai Co., Ltd., Shanghai, China). All experiments were repeated three times.

Tumorigenicity assays in nude mice. Male BALB/c nude mice (aged 3-4 weeks) were purchased from the Department of Laboratory Animal Center of Nanjing Medical University. Cells with differential miR-497 expression were injected subcutaneously into the lateral root of the anterior limb of the nude mice $\left(5.00 \times 10^{6}\right.$ cells/mouse; 6 mice/experimental group). Tumor size was measured every third day following injection. At 3 weeks after injection, mice were sacrificed via cervical dislocation and tumors were excised and photographed. The weights of the tumors were also recorded. Experimental animals were maintained in accordance with Institutional Animal Care and Use Committee guidelines (38).

Western blot analyses. Cell lysates were prepared using cold lysis buffer containing $25 \mathrm{mM}$ Tris- $\mathrm{Cl}$ (pH 7.5), $5 \mathrm{mM}$ EDTA, $1 \%$ sodium dodecyl sulfate (SDS), and a protease inhibitor cocktail (Sigma-Aldrich, St. Louis, MO, USA).
A

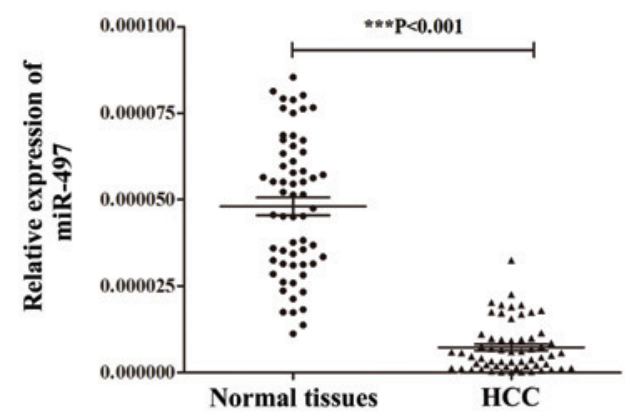

B

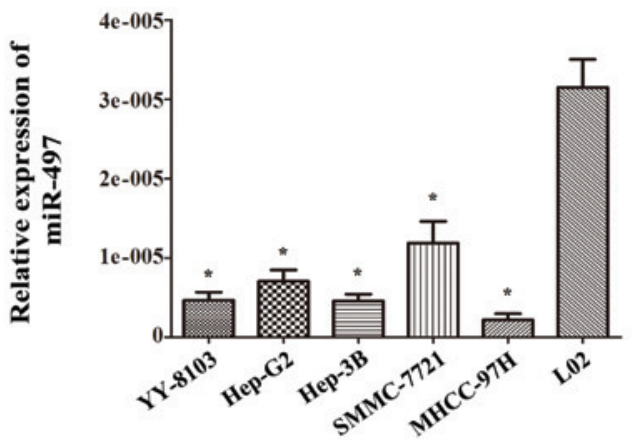

C

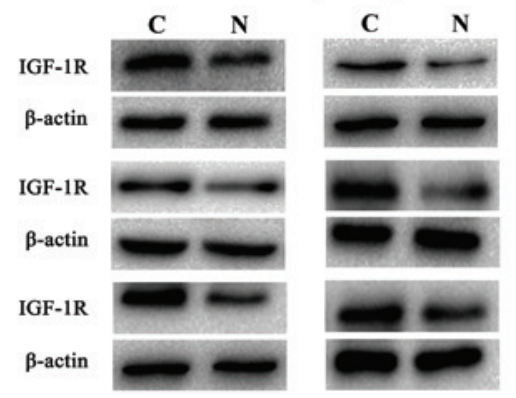

D
$100 x$

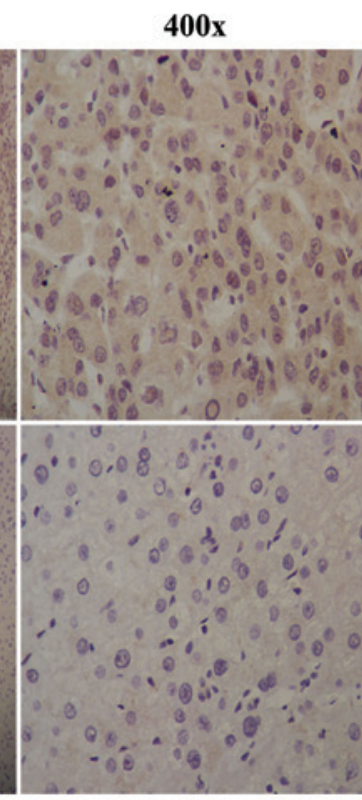

Figure 1. Downregulation of miR-497 and upregulation of IGF-1R in HCC qPCR results indicated that miR-497 expression was downregulated (A) in 60 paired HCC specimens relative to matched adjacent normal tissue $\left({ }^{* * * *} \mathrm{P}<0.001\right)$, and $(\mathrm{B})$ in five HCC-derived cell lines compared with L02 normal human liver cells $\left({ }^{*} \mathrm{P}<0.05\right)$. (C) Representative western blot results showing IGF-1R protein upregulation in HCC specimens. (D) Representative immunohistochemistry results showing upregulation of IGF-1R in HCC compared with non-HCC specimens (magnification, $\mathrm{x} 100$ and $\mathrm{x} 400$ ). miR, microRNA; IGF-1R, insulin-like growth factor-1 receptor; HCC, hepatocellular carcinoma; qPCR, quantitative polymerase chain reaction; $\mathrm{C}$, cancer tissue; $\mathrm{N}$, adjacent non-cancerous tissue. 
A

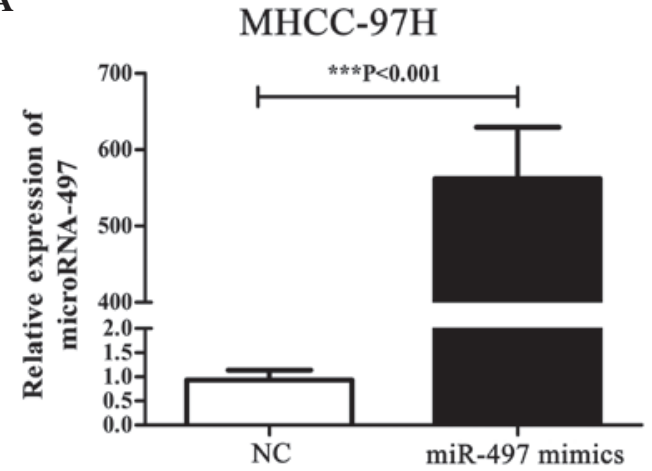

C

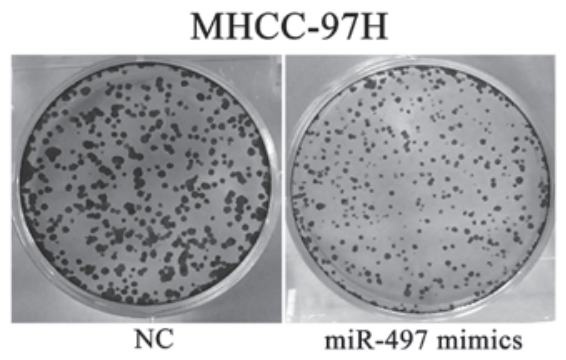

$\mathbf{E}$

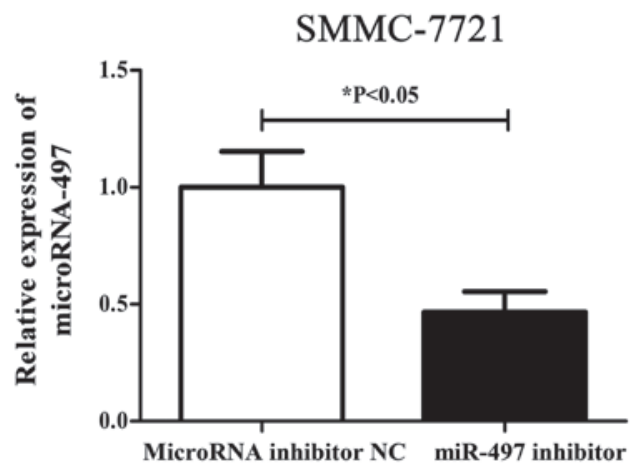

G
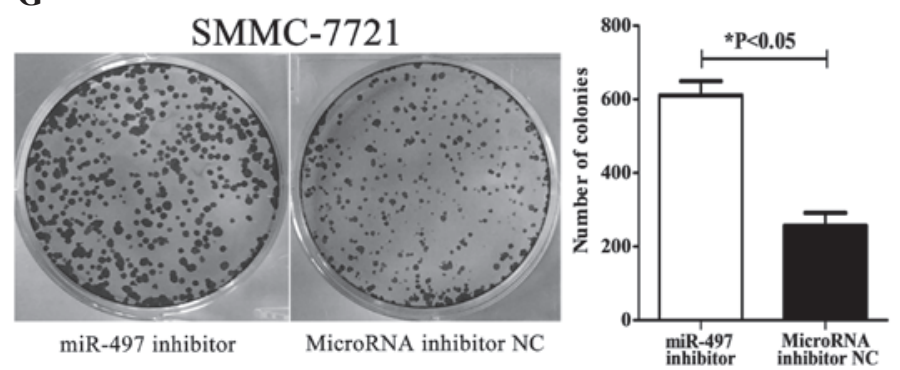

B

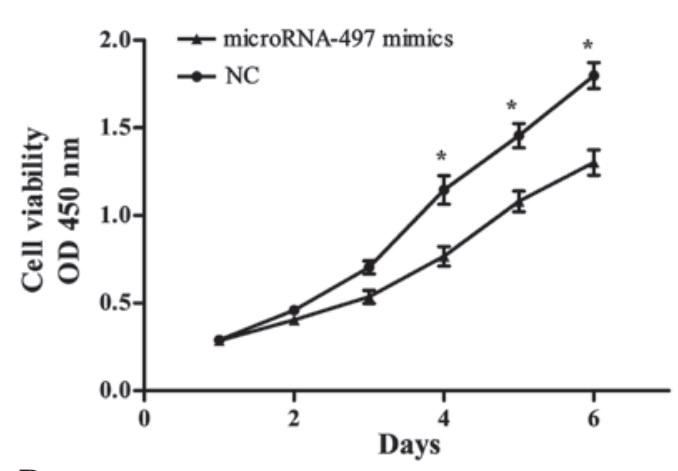

D
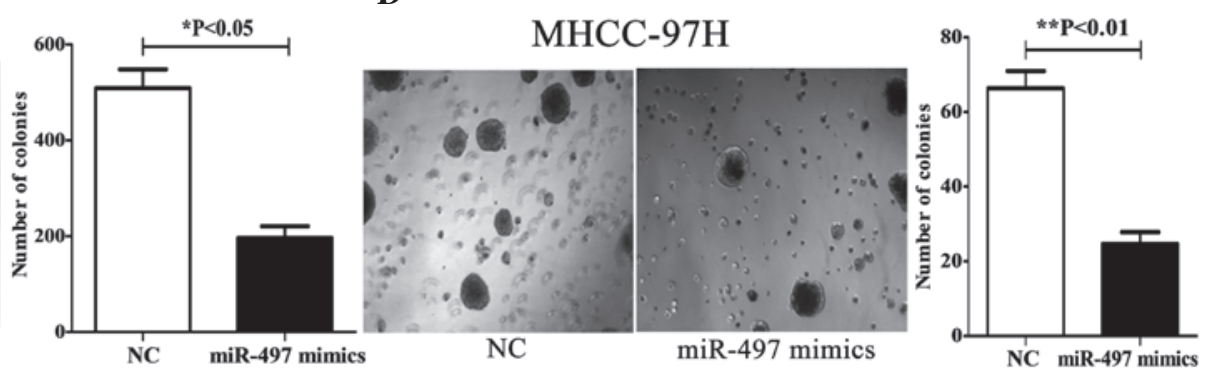

$\mathbf{F}$

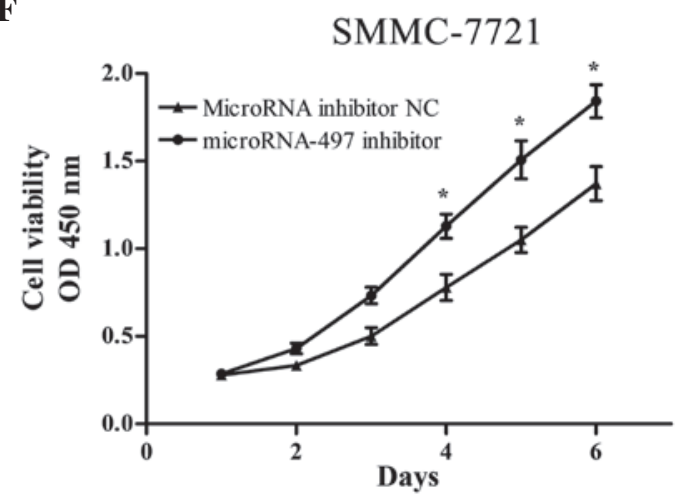

$\mathbf{H}$
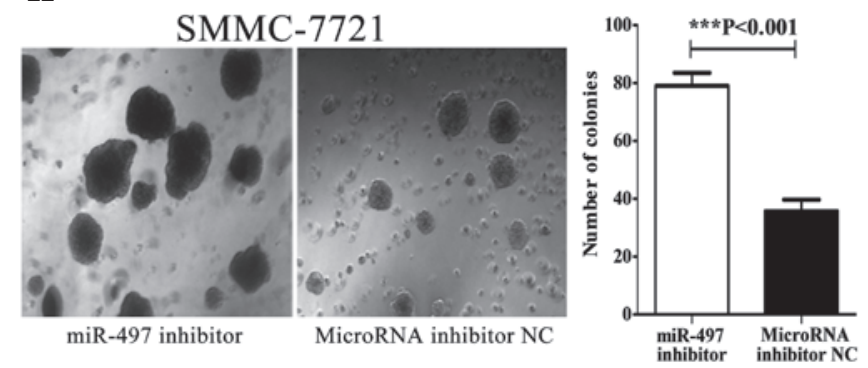

Figure 2. Differential expression of miR-497 influences cell proliferation and colony formation. (A) qPCR confirmed that MHCC-97H cells transfected with miR-497 mimics exhibit increased miR-497 expression compared with NC-transfected cells $\left({ }^{* * *} \mathrm{P}<0.001\right),(\mathrm{B}) \mathrm{miR}-497$ overexpression inhibits MHCC-97H cell proliferation ("P<0.05). (C) miR-497 overexpression inhibits colony formation of MHCC-97H cells ("P<0.05). (D) Overexpression of miR-497 inhibits soft agar colony formation of MHCC-97H cells ("* $\mathrm{P}<0.01$ ). (E) SMMC-7721 cells transfected with the miR-497 inhibitor had decreased miR-497 expression compared with inhibitor NC-transfected cells ("P<0.05). (F) miR-497 silencing promotes proliferation of SMMC-7721 cells ("P<0.05). (G) miR-497 silencing promotes colony formation of SMMC-7721 cells ( $\mathrm{P}<0.05)$. (H) miR-497 silencing promotes soft agar colony formation of SMMC-7721 cells $\left({ }^{* * *} \mathrm{P}<0.001\right)$. miR, microRNA; NC, negative control; OD, optical density.

Protein concentration was subsequently determined using a bicinchoninic acid assay kit (Thermo Fisher Scientific, Rockford, IL, USA). After boiling for $5 \mathrm{~min}$, samples were subjected to $10 \%$ SDS-polyacrylamide gel electrophoresis and transferred to polyvinylidene difluoride membranes (EMD Millipore, Billerica, MA, USA). Membranes were blocked for $1 \mathrm{~h}$ at room temperature with 5\% blocking buffer (Inner Mongolia Yili Industrial Group Co., Ltd., Inner Mongolia, China), washed three times with Tris-buffered saline containing $0.1 \%$ Tween-20, and incubated overnight at $4^{\circ} \mathrm{C}$ with rabbit anti-human polyclonal primary antibodies against IGF-1R (cat. no. ab39398; dilution, 1:100; Abcam), p21 (cat. no. ab109199; dilution, 1:1,000; Abcam), p27 (cat. no. ab32034; dilution, 1:1,000; Abcam), 
phospho- (p-) Ser473 Akt (cat. no. ab126433; dilution, 1:1,000; Abcam), p-glycogen synthase kinase $3 \beta$ (GSK3 $\beta$; cat. no. ab75745; dilution, 1:1,000; Abcam) and $\beta$-actin (cat. no. ab119716; dilution, 1:1,000; Abcam). After the membranes were washed, they were incubated for $1 \mathrm{~h}$ at room temperature with the mouse anti-rabbit $\operatorname{IgG}$ secondary antibody (cat. no. bs-0295M; dilution, 1:1,000; Beijing Biosynthesis Biotechnology Co., Ltd., Beijing, China). Proteins were detected by enhanced chemiluminescence (ECL) using a Pierce ${ }^{\mathrm{TM}}$ ECL Western Blotting detection system (Thermo Fisher Scientific, Inc., Rockford, IL, USA). $\beta$-actin was used as the internal control.

Statistical analyses. Statistical analyses were performed using SPSS version 18.0 (SPSS, Inc., Chicago, IL, USA) and GraphPad Prism 5.0 software (GraphPad Software, Inc., La Jolla, CA, USA). Quantitative data are presented as the mean \pm standard deviation. Differences between two groups were assessed using a Student's t-test (two-tailed). $\mathrm{P}<0.05$ was considered to indicate statistically significant differences.

\section{Results}

$H C C$ exhibits decreased miR-497 expression and increased IGF-1R expression. qPCR was performed to measure miR-497 expression levels in HCC and adjacent non-cancerous liver tissues from 60 patients. miR-497 expression was observed to be decreased compared with matched normal liver tissues in 42/60 (70.0\%) HCC specimens ( $\mathrm{P}<0.001$; Fig. 1A). Next, the expression of miR-497 was evaluated in five HCC-derived cell lines using qPCR. miR-497 expression was significantly reduced in all HCC-derived cell lines (YY-8103, HepG2, Hep3B, SMMC-7721 and MHCC-97H) compared with L02 normal human liver cells (Fig. 1B). Of the five HCC-derived cell lines, MHCC-97H cells exhibited the lowest level of miR-497 expression, whereas SMMC-7721 exhibited the highest level of miR-497 expression (Fig. 1B). One of the predicted common targets of miR-497 is IGF-1R (http://mirtarbase.mbc.nctu.edu.tw/php/search.php?q= search_exact\&searchword=hsa-miR-497-5p). Therefore, western blot analysis was conducted to measure IGF-1R protein levels in HCC and adjacent non-cancer tissue. The results indicated that IGF-1R protein expression was increased in HCC specimens compared with matched normal liver tissues (Fig. 1C). Immunohistochemistry was also used to evaluate IGF-1R protein expression in HCC specimens and paired normal tissues in the same 60 matched samples. Of these specimens, 24/60 (40.0\%) cancerous specimens exhibited no or weak positive staining, whereas 45/60 (75.0\%) non-HCC tissues showed no or weak positive staining (Fig. 1D). Collectively, these data indicate that miR-497 expression is decreased and IGF-1R expression is increased in HCC tissues.

miR-497 overexpression inhibits proliferation and colony formation in MHCC-97H cells. To overexpress miR-497, miR-497 mimics were transfected into MHCC-97H cells, which exhibited the lowest level of miR-497 expression among the 5 HCC-derived cell lines. qPCR was used to evaluate miR-497 expression in transfected cells at $24 \mathrm{~h}$ post transfection.InmiR-497 mimic-transfected cells, miR-497 expression was significantly higher compared with that of miR-497 NC-transfected cells (Fig. 2A). To investigate the effects on proliferation in miR-497 mimic-transfected cells, cell growth was monitored for 6 days. miR-497 mimic-transfected MHCC-97H cells exhibited significantly reduced cell proliferation compared with that of miR-497 NC-transfected cells (Fig. 2B) $(\mathrm{P}<0.05)$. MHCC-97H cells with upregulated miR-497 expression were subjected to colony formation assays. As shown in Fig. 2C, miR-497 overexpression in MHCC-97H cells significantly inhibited colony formation relative to $\mathrm{MHCC}-97 \mathrm{H}$ cells transfected with miR-497 NC $(\mathrm{P}<0.05)$; furthermore, the majority of clones were smaller than those of control cells. Next, soft agar assays were utilized to assess colony formation; these are the most stringent assays for detecting the proliferative ability of cells (39). Reduced colony formation was observed in soft agar (Fig. 2D) that had been seeded with MHCC-97H cells transfected with miR-497 mimics, compared with that seeded with miR-497 NC-transfected cells $(\mathrm{P}<0.01)$. These results indicate that miR-497 inhibits tumor cell growth in vitro.

miR-497 knockdown promotes proliferation and colony formation in SMMC-7721 cells. To knockdown miR-497, a miR-497 inhibitor was transfected into SMMC-7721 cells, which exhibited the highest level of miR-497 expression among the $5 \mathrm{HCC}$-derived cell lines. qPCR was performed to assess the efficiency of miR-497 knockdown in these cells, confirming that miR-497 expression in miR-497 inhibitor-transfected cells was significantly lower compared to miRNA inhibitor NC-transfected cells (Fig. 2E). miR-497 inhibitor-transfected SMMC-7721 cells (Fig. 2F) exhibited enhanced cell proliferation compared with miRNA inhibitor NC-transfected cells $(\mathrm{P}<0.05)$. Next, SMMC-7721 cells with downregulated miR-497 expression were subjected to colony formation assays. As shown in Fig. 2G, decreased miR-497 expression in SMMC-7721 cells significantly promoted colony formation relative to cells transfected with the miRNA inhibitor $\mathrm{NC}(\mathrm{P}<0.05)$. Enhanced colony formation in soft agar (Fig. 2H) was also observed in SMMC-7721 cells transfected with the miR-497 inhibitor compared with miRNA inhibitor NC-transfected cells $(\mathrm{P}<0.001)$.

Differential expression of miR-497 affects tumorigenesis in nude mice. The effects of differential miR-497 expression on the tumorigenic potential of HCC cells were investigated in vivo. MHCC-97H cells with upregulated miR-497 expression and SMMC-7721 cells with downregulated miR-497 expression were injected subcutaneously into BALB/c nude mice. Tumor size was measured on every third day following injection. After 3 weeks, mice were sacrificed and the excised tumors were photographed and weighed. Results are shown in Fig. 3. Compared to mice injected with MHCC-97H cells transfected with miR-497 NC, mice injected with MHCC-97H cells overexpressing miR-497 exhibited smaller tumors during the same time period, and the mean tumor volumes and weights were significantly lower than the control group $(\mathrm{P}<0.05)$ (Fig. 3A, C, and E). Compared with mice injected with miRNA inhibitor NC-transfected SMMC-7721 cells, mice injected with miR-497-underexpressing SMMC-7721 cells exhibited an increased capacity for tumorigenesis $(\mathrm{P}<0.05)$ (Fig. 3B, D and F). Taken together, these 
A

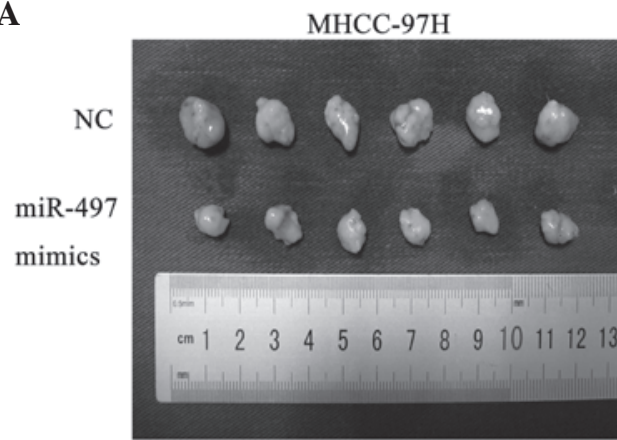

C

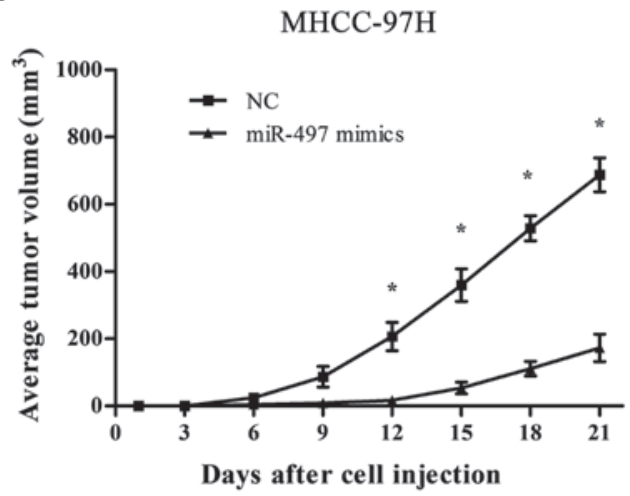

$\mathbf{E}$

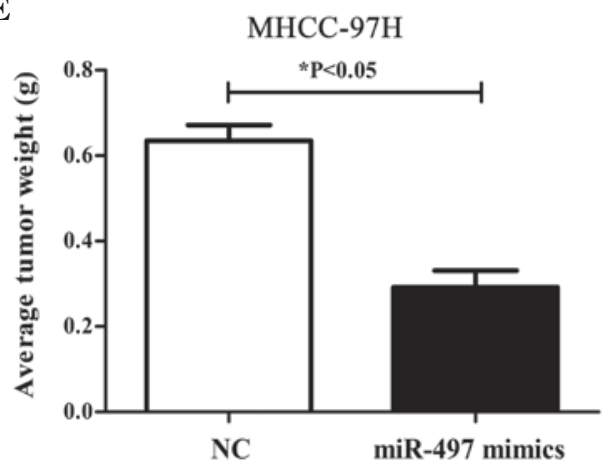

B

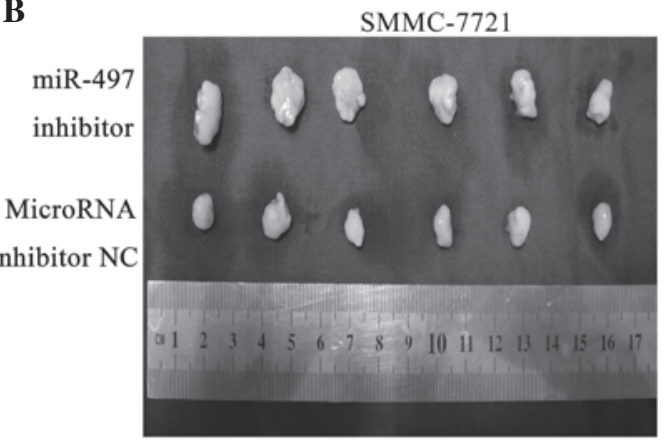

D

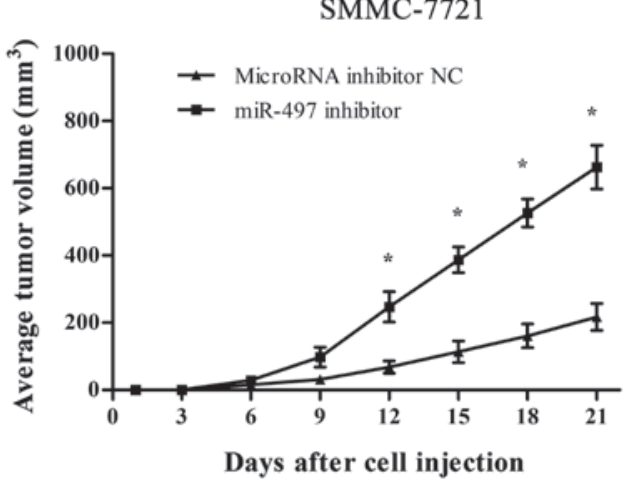

$\mathbf{F}$

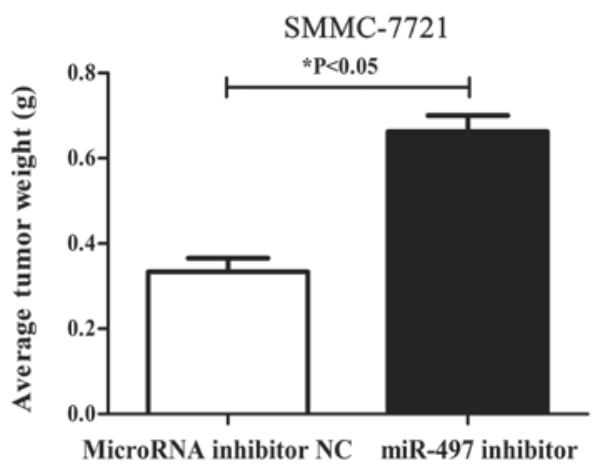

Figure 3. The effect of miR-497 expression on tumorigenesis in nude mice. (A and B) Tumors were excised 21 days after injection of cells. (C and D) Tumor volumes were measured every third day after injection $\left({ }^{*} \mathrm{P}<0.05\right)$. ( $\mathrm{E}$ and $\left.\mathrm{F}\right)$ The average (mean) weight of tumors in each group was assessed $\left({ }^{*} \mathrm{P}<0.05\right)$. miR, microRNA; NC, negative control.

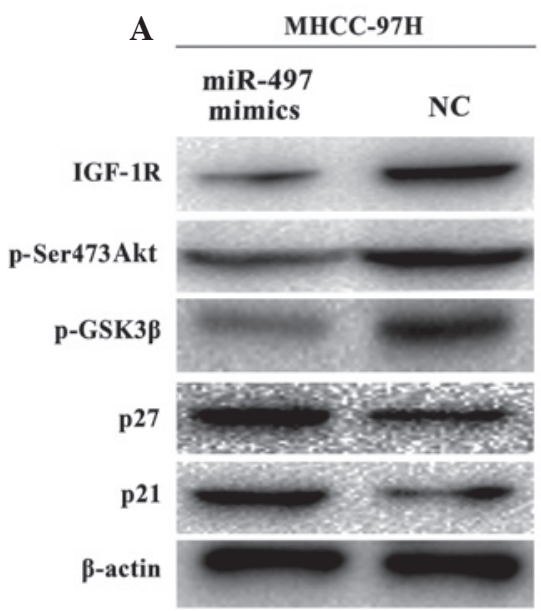

$\mathbf{B}$

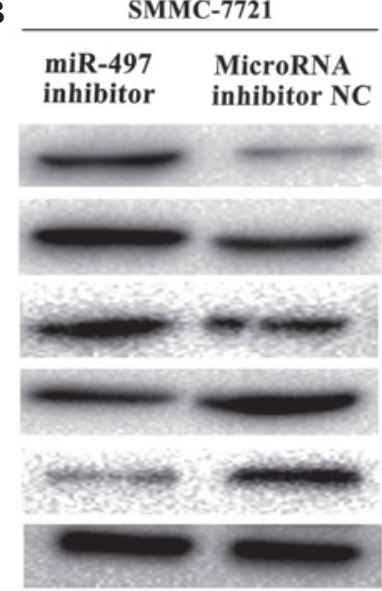

Figure 4. Western blot analyses of the phosphoinositide 3-kinase/Akt signaling pathway and cyclin pathway-related proteins. (A) Upregulation of p21 and p27 and downregulation of IGF-1R, pSer-473 Akt and p-GSK3 $\beta$ in miR-497-overexpressed MHCC-97H cells. (B) Downregulation of p21 and p27, and upregulation of IGF-1R, pSe-473 Akt and p-GSK3 $\beta$ in miR-497-silenced SMMC-7721 cells. miR, microRNA; NC, negative control; IGF-1R, insulin-like growth factor-1 receptor; GSK3 $\beta$, p-glycogen synthase kinase $3 \beta$. 
results strongly suggest that miR-497 inhibits tumor cell growth and tumorigenicity in vivo.

miR-497 expression affects PI3K/Akt signaling and the expression of cyclin pathway-related proteins. To determine the mechanism(s) by which miR-497 regulates tumor growth and progression, potential miR-497-regulated molecules were examined in HCC cell lines with upregulated or downregulated miR-497 expression. Protein expression data revealed upregulation of p21 and p27, and downregulation of IGF-1R, p-Ser473 Akt and p-GSK3 $\beta$ in miR-497-overexpressing MHCC-97H cells (Fig. 4A). Conversely, miR-497 silencing by the miR-497 inhibitor in SMMC-7721 cells led to downregulation of $\mathrm{p} 21$ and $\mathrm{p} 27$, and upregulation of IGF-1R, p-Ser-473 Akt and p-GSK3 $\beta$ (Fig. 4B).

\section{Discussion}

HCC is the fifth most frequent cancer worldwide (40). A series of risk factors contribute to $\mathrm{HCC}$ occurrence, including infection with hepatitis $\mathrm{B}$ and $\mathrm{C}$ viruses, cirrhosis, chemical exposure, radiation and type 2 diabetes $(41,42)$. Because surgical resection is only suitable for patients diagnosed with early stage disease, systemic chemotherapy remains an indispensable treatment option despite serious adverse reactions (43). Recently, increasing evidence suggests that miRNAs are involved in hepatocarcinogenesis, thus opening new avenues of investigation into the underlying molecular mechanism(s) of $\mathrm{HCC}$, as well as providing potential new therapeutic targets (44).

The current study focused on miRNA-497, which was previously demonstrated to exhibit decreased expression in numerous tumor types, and which may function as a tumor suppressor (12-20). The results confirmed that the expression levels of miRNA-497 are decreased in HCC tumor tissues or HCC-derived cell lines compared with adjacent non-cancerous tissues or normal human L02 hepatocytes. Previously, Furuta et al (21) reported that miR-497 suppressed cell growth by targeting multiple cell-cycle regulators in HCC (21). These results were consistent with those of the current in vitro experiments in which exogenous overexpression of miRNA-497 was observed to inhibit MHCC-97H colony formation and tumor growth.

IGF-1R, a target gene of miR-497, was also selected for investigation; overexpression of this gene has been reported in human cervical cancer and colorectal cancer $(12,20)$. Furthermore, several online databases, including miRanda (http://www.microrna.org/microrna/getMrna.do?gene $=3480$ \&utr=31402\&organism=9606\&matureName=hsa-miR-497) and miRTarBase (http://mirtarbase.mbc.nctu.edu.tw/php/ search.php?q=search_exact\&searchword=hsa-miR-497-5p), indicated that IGF-1R mRNA contains miR-497 binding sites. IGF-1R belongs to the receptor tyrosine kinase family, and is activated by insulin-like growth factor (IGF)-1 and IGF-2 with high affinities. IGF-1R is a crucial component of the IGF axis that promotes cell proliferation, migration, and transformation $(45,46)$. Previous studies have reported that IGF-1R expression is increased in HCC and is closely associated with tumor progression $(34,35)$. In the current study, western blot and immunohistochemical analyses revealed that IGF-1R was upregulated in HCC samples. As the PI3K/Akt signaling pathway is often activated in $\mathrm{HCC}$, and is partially activated by IGF-1R $(29,30,47)$, western blot analyses were employed to investigate components of this pathway. The results revealed that miR-497 overexpression reduced IGF-1R expression and decreased PI3K/Akt pathway activation. Changes were detected in downstream targets, including decreased phosphorylation of Akt (Ser473) and GSK3 3 , and increased expression of p27 and p21. Conversely, miR-497 silencing resulted in increased IGF-1R expression and elevated activation of PI3K/Akt signalling. These results indicate that miR-497 regulates PI3K/Akt pathway activation, consistently with results from a previous study on human colorectal cancer (12). Notably, both miRNA-497 and p53 cluster at 17p13.1 (21), and wild-type p53 inhibits IGF-1R expression, whereas mutant p53 increases IGF-1R expression $(48,49)$. These findings suggest that abnormal transcription or translation of the chromosome 17p13.1 fragment may play a crucial role in hepatocarcinogenesis.

In conclusion, the current results verify that miRNA-497 downregulation occurs frequently during hepatocarcinogenesis. miRNA-497 overexpression may suppress cellular growth by targeting IGF-1R and inhibiting activation of the PI3K/Akt pathway in HCC-derived cell lines. Currently, a series of antibodies and small molecule inhibitors targeting the IGF axis may provide an alternative strategy in the management of HCC (50). Therefore, artificial upregulation of miRNA-497 may also provide a new therapeutic option for HCC.

\section{Acknowledgements}

This study was supported by a grant from the Natural Science Foundation of China (no. 81270483).

\section{References}

1. Bosch FX, Ribes J, Díaz M and Cléries R: Primary liver cancer: Worldwide incidence and trends. Gastroenterology 127 (Suppl 1): S5-S16, 2004.

2. Cabrera R and Nelson DR: Review article: The management of hepatocellular carcinoma. Aliment Pharmacol Ther 31: 461-476, 2010.

3. Caldwell S and Park SH: The epidemiology of hepatocellular cancer: From the perspectives of public health problem to tumor biology. J Gastroenterol 44 (Suppl 19): 96-101, 2009.

4. Bosch FX, Ribes J and Borràs J: Epidemiology of primary liver cancer. Semin Liver Dis 19: 271-285, 1999.

5. Tsuchiya N, Sawada Y, Endo I, et al: Biomarkers for the early diagnosis of hepatocellular carcinoma. World J Gastroenterol 21: 10573-10583, 2015.

6. Bruix J and Sherman M; Practice Guidelines Committee, American Association for the Study of Liver Diseases: Management of hepatocellular carcinoma. Hepatology 42: 1208-1236, 2005

7. Bartel DP: MicroRNAs: Genomics, biogenesis, mechanism, and function. Cell 116: 281-297, 2004.

8. Winter J, Jung S, Keller S, Gregory RI and Diederichs S: Many roads to maturity: microRNA biogenesis pathways and their regulation. Nat Cell Biol 11: 228-234, 2009.

9. Bartel DP: MicroRNAs: Target recognition and regulatory functions. Cell 136: 215-233, 2009.

10. He L and Hannon GJ: MicroRNAs: Small RNAs with a big role in gene regulation. Nat Rev Genet 5: 522-531, 2004.

11. Vasudevan S, Tong Y and Steitz JA: Switching from repression to activation: microRNAs can up-regulate translation. Science 318: 1931-1934, 2007. 
12. Guo ST, Jiang CC, Wang GP, Li YP, Wang CY, Guo XY, Yang RH, Feng Y, Wang FH, Tseng HY, et al: MicroRNA-497 targets insulin-like growth factor 1 receptor and has a tumour suppressive role in human colorectal cancer. Oncogene 32: 1910-1920, 2013.

13. Luo Q, Li X, Gao Y, Long Y, Chen L, Huang Y and Fang L: MiRNA-497 regulates cell growth and invasion by targeting cyclin E1 in breast cancer. Cancer Cell Int 13: 95, 2013.

14. Poell JB, van Haastert RJ, de Gunst T, Schultz IJ, Gommans WM, Verheul M, Cerisoli F, van Noort PI, Prevost GP, Schaapveld RQ, et al: A functional screen identifies specific microRNAs capable of inhibiting human melanoma cell viability. PLoS One 7: e43569, 2012.

15. Zhu W, Zhu D, Lu S, Wang T, Wang J, Jiang B, Shu Y and Liu P: miR-497 modulates multidrug resistance of human cancer cell lines by targeting BCL2. Med Oncol 29: 384-391, 2012.

16. Shen L, Li J, Xu L, Ma J, Li H, Xiao X, Zhao J and Fang L: miR-497 induces apoptosis of breast cancer cells by targeting Bcl-w. Exp Ther Med 3: 475-480, 2012.

17. Lehmann U, Streichert T, Otto B, Albat C, Hasemeier B, Christgen H, Schipper E, Hille U, Kreipe HH and Länger F: Identification of differentially expressed microRNAs in human male breast cancer. BMC Cancer 10: 109, 2010

18. Li D, Zhao Y, Liu C, Chen X, Qi Y, Jiang Y, Zou C, Zhang X, Liu S, Wang X, et al: Analysis of MiR-195 and MiR-497 expression, regulation and role in breast cancer. Clin Cancer Res 17: 1722-1730, 2011.

19. Özata DM, Caramuta S, Velázquez-Fernández D, Akçakaya P, Xie H, Höög A, Zedenius J, Bäckdahl M, Larsson C and Lui WO: The role of microRNA deregulation in the pathogenesis of adrenocortical carcinoma. Endocr Relat Cancer 18: 643-655, 2011

20. Luo M, Shen D, Zhou X, Chen X and Wang W: MicroRNA-497 is a potential prognostic marker in human cervical cancer and functions as a tumor suppressor by targeting the insulin-like growth factor 1 receptor. Surgery 153: 836-847, 2013.

21. Furuta M, Kozaki K, Tanimoto K, Tanaka S, Arii S, Shimamura T, Niida A, Miyano S and Inazawa J: The tumor-suppressive miR-497-195 cluster targets multiple cell-cycle regulators in hepatocellular carcinoma. PLoS One 8: e60155, 2013.

22. LeRoith D and Helman L: The new kid on the block(ade) of the IGF-1 receptor. Cancer Cell 5: 201-202, 2004.

23. Pollak M: Insulin and insulin-like growth factor signalling in neoplasia. Nat Rev Cancer 8: 915-928, 2008.

24. Morrione A, DeAngelis T and Baserga R: Failure of the bovine papillomavirus to transform mouse embryo fibroblasts with a targeted disruption of the insulin-like growth factor I receptor genes. J Virol 69: 5300-5303, 1995.

25. Valentinis B and Baserga R: IGF-I receptor signalling in transformation and differentiation. Mol Pathol 54: 133-137, 2001.

26. Hellawell GO, Turner GD, Davies DR, Poulsom R, Brewster SF and Macaulay VM: Expression of the type 1 insulin-like growth factor receptor is up-regulated in primary prostate cancer and commonly persists in metastatic disease. Cancer Res 62: 2942-2950, 2002

27. Tomizawa M, Shinozaki F, Sugiyama T, Yamamoto S, Sueishi $\mathrm{M}$ and Yoshida T: Insulin-like growth factor-I receptor in proliferation and motility of pancreatic cancer. World J Gastroenterol 16: 1854-1858, 2010.

28. Kornprat $\mathrm{P}$, Rehak $\mathrm{P}$, Rüschoff $\mathrm{J}$ and Langner $\mathrm{C}$ : Expression of IGF-I, IGF-II, and IGF-IR in gallbladder carcinoma. A systematic analysis including primary and corresponding metastatic tumours. J Clin Pathol 59: 202-206, 2006.

29. Weber MM, Fottner C, Liu SB, Jung MC, Engelhardt D and Baretton GB: Overexpression of the insulin-like growth factor I receptor in human colon carcinomas. Cancer 95: 2086-2095, 2002.
30. Sekharam M, Zhao H, Sun M, Fang Q, Zhang Q, Yuan Z, Dan HC, Boulware D, Cheng JQ and Coppola D: Insulin-like growth factor 1 receptor enhances invasion and induces resistance to apoptosis of colon cancer cells through the Akt/Bcl-x(L) pathway. Cancer Res 63: 7708-7716, 2003.

31. Cantley LC: The phosphoinositide 3-kinase pathway. Science 296: 1655-1657, 2002.

32. Markman B, Atzori F, Pérez-García J, Tabernero J and Baselga $\mathrm{J}$ : Status of PI3K inhibition and biomarker development in cancer therapeutics. Ann Oncol 21: 683-691, 2010.

33. Hanahan D and Weinberg RA: The hallmarks of cancer. Cell 100: 57-70, 2000.

34. Scharf JG, Schmidt-Sandte W, Pahernik SA, Ramadori G, Braulke T and Hartmann H: Characterization of the insulin-like growth factor axis in a human hepatoma cell line (PLC). Carcinogenesis 19: 2121-2128, 1998.

35. Zhang YC, Wang XP, Zhang LY, Song AL, Kou ZM and Li XS: Effect of blocking IGF-I receptor on growth of human hepatocellular carcinoma cells. World J Gastroenterol 12: 3977-3982, 2006.

36. Llovet JM, Brú C and Bruix J: Prognosis of hepatocellular carcinoma: The BCLC staging classification. Semin Liver Dis 19: 329-338, 1999.

37. Livak KJ and Schmittgen TD: Analysis of relative gene expression data using real-time quantitative PCR and the 2(-Delta Delta C(T)) Method. Methods 25: 402-408, 2001.

38. National Research Council (US) Committee for the Update of the Guide for the Care and Use of Laboratory Animals: Guide for the Care and Use of Laboratory Animals. 8th edition. National Academies Press, Washington, WA, 2011.

39. Ni QF, Tian Y, Kong LL, Lu YT, Ding WZ and Kong LB: Latexin exhibits tumor suppressor potential in hepatocellular carcinoma. Oncol Rep 31: 1364-1372, 2014.

40. Anwar SL and Lehmann U: MicroRNAs: Emerging novel clinical biomarkers for hepatocellular carcinomas. J Clin Med 4. 1631-1650, 2015

41. Llovet JM and Bruix J: Molecular targeted therapies in hepatocellular carcinoma. Hepatology 48: 1312-1327, 2008.

42. Vigneri P, Frasca F, Sciacca L, Pandini G and Vigneri R: Diabetes and cancer. Endocr Relat Cancer 16: 1103-1123, 2009.

43. Laca L, Dedinska I, Miklusica J, Janik J, Palkoci B and Pindura M: Surgical treatment of hepatocellular carcinoma. Bratisl Lek Listy 116: 539-541, 2015.

44. Iorio MV and Croce CM: MicroRNA dysregulation in cancer: Diagnostics, monitoring and therapeutics. A comprehensive review. EMBO Mol Med 4: 143-159, 2012.

45. Pollak MN, Schernhammer ES and Hankinson SE: Insulin-like growth factors and neoplasia. Nat Rev Cancer 4: 505-518, 2004.

46. Khandwala HM, McCutcheon IE, Flyvbjerg A and Friend KE: The effects of insulin-like growth factors on tumorigenesis and neoplastic growth. Endocr Rev 21: 215-244, 2000.

47. Xu X, Sakon M, Nagano H, Hiraoka N, Yamamoto H, Hayashi N, Dono K, Nakamori S, Umeshita K, Ito Y, et al: Akt2 expression correlates with prognosis of human hepatocellular carcinoma. Oncol Rep 11: 25-32, 2004

48. LeRoith D and Roberts CT Jr: The insulin-like growth factor system and cancer. Cancer Lett 195: 127-137, 2003.

49. Sjögren K, Liu JL, Blad K, Skrtic S, Vidal O, Wallenius V, LeRoith D, Törnell J, Isaksson OG, Jansson $\mathrm{JO}$, et al: Liver-derived insulin-like growth factor I (IGF-I) is the principal source of IGF-I in blood but is not required for postnatal body growth in mice. Proc Natl Acad Sci USA 96: 7088-7092, 1999.

50. Wu J and Zhu AX: Targeting insulin-like growth factor axis in hepatocellular carcinoma. J Hematol Oncol 4: 30, 2011. 